\title{
Research Article \\ Selective Surface Sintering Using a Laser-Induced Breakdown Spectroscopy System
}

\author{
H. Jull, ${ }^{1,2}$ P. Ewart, ${ }^{1,3}$ R. Künnemeyer, ${ }^{1,2}$ and P. Schaare ${ }^{4}$ \\ ${ }^{1}$ School of Engineering, University of Waikato, Hamilton 3240, New Zealand \\ ${ }^{2}$ The Dodd-Walls Centre for Photonic and Quantum Technologies, Hamilton 3240, New Zealand \\ ${ }^{3}$ Waikato Institute of Technology, Hamilton 3200, New Zealand \\ ${ }^{4}$ The New Zealand Institute for Plant \& Food Research Ltd, Hamilton 3240, New Zealand
}

Correspondence should be addressed to H. Jull; harrisson.jull@gmail.com

Received 27 March 2017; Revised 24 May 2017; Accepted 30 May 2017; Published 27 July 2017

Academic Editor: Violeta Lazic

Copyright (c) $2017 \mathrm{H}$. Jull et al. This is an open access article distributed under the Creative Commons Attribution License, which permits unrestricted use, distribution, and reproduction in any medium, provided the original work is properly cited.

\begin{abstract}
Titanium metal injection molding allows creation of complex metal parts that are lightweight and biocompatible with reduced cost in comparison with machining titanium. Laser-induced breakdown spectroscopy (LIBS) can be used to create plasma on the surface of a sample to analyze its elemental composition. Repetitive ablation on the same site has been shown to create differences from the original sample. This study investigates the potential of LIBS for selective surface sintering of injection-molded titanium metal. The temperature created throughout the LIBS process on the surface of the injection-molded titanium is high enough to fuse together the titanium particles. Using the ratio of the Ti II $282.81 \mathrm{~nm}$ and the C I $247.86 \mathrm{~nm}$ lines, the effectiveness of repetitive plasma formation to produce sintering can be monitored during the process. Energy-dispersive X-ray spectroscopy on the ablation craters confirms sintering through the reduction in carbon from $20.29 \mathrm{Wt} \%$ to $2.13 \mathrm{Wt}$. $\%$. Scanning electron microscope images confirm sintering. A conventional LIBS system, with a fixed distance, investigated laser parameters on injection-molded and injection-sintered titanium. To prove the feasibility of using this technique on a production line, a second LIBS system, with an autofocus and 3-axis translation stage, successfully sintered a sample with a nonplanar surface.
\end{abstract}

\section{Introduction}

Metal injection molding (MIM) is a fabrication method that uses the injection molding process and sintering to create metal parts with complex geometry (parts with varying surface heights). This process combines metal powders with a carrier system or binder, containing thermoplastic polymers and waxes to create a feedstock that can be injected into a mold to form a green part [1]. The binder is then gradually removed from the green part by a solvent debinding method, a thermal debinding method, or a combination of both. The part is then referred to as a brown part and is sintered in a furnace at high temperature whereby the particles coalesce or fuse together to form a fully consolidated metal part. Using titanium (Ti) metal in MIM allows parts to be created that are both light in weight and biocompatible [2]. The complex shapes formed offer a reduction in costs associated with titanium parts made by conventional fabrication processes such as casting or machining and can even form parts not possible to produce by any other means. However, powder metallurgy (PM) is known to produce parts with mechanical properties inferior to those produced from wrought metals due to stress raisers and surface irregularities resulting from incomplete particle coalescence. Incomplete coalescence of titanium PM parts is known to occur due to low-quality starting powders, low sintering time, or temperature and also contaminated furnace atmosphere, all of which affect the outermost surface. These surface defects may be mitigated by optimizing the sinter cycle, secondary processes such as bead blasting and polishing or treatments such as electropolishing and coating.

Titanium MIM has the added problem of contamination through any residual binder components of which carbon and oxygen are the most prevalent and the most difficult to mitigate. The transformation of the titanium lattice structure during sintering is influenced by these impurities, and the 
formation of oxides/carbides also impinges on the coalescence. While the saturation levels of interstitial oxygen (wo $\leq 5 \%$ ) are high, carbon compounds readily form on powder surfaces above $370^{\circ} \mathrm{C}$. The presence of carbon on the titanium particles interferes with heat transfer, the oxide presence means the detection, and quantification of the elemental levels is difficult.

Sintering of metals can also be done with high-powered continuous wave (CW) lasers such as those used in direct metal laser sintering and selective laser sintering. This process requires a high-power density over a short time [3]. Laser-induced breakdown spectroscopy (LIBS) uses a highpower pulsed laser to ablate the surface of a sample and to create a plasma that contains the surface elements. The study presented here investigates whether LIBS can be used for selective surface sintering of injection-molded titanium while simultaneously measuring the amount of sintering that has taken place.

1.1. Laser-Induced Breakdown Spectroscopy. LIBS is a form of optical emission spectroscopy utilizing a high-powered, pulsed laser. The short pulse is focused onto a sample surface where it creates a high-power density in a localized area. A plasma is created from the ablated material [4]. Plasma formation is a complex process, which is still under investigation. The current models for ablation describing the change in thermal properties of the sample material are adequate for this study [5]. The models for nanosecond laser ablation state that when a laser hits a target, with enough high energy, the surface heats up, melts, vaporizes, and ionizes creating a plasma. If there is additional energy in the laser pulse, the plasma absorbs it, increasing the plasma temperature. Further heating of the surface of the target can occur if the plasma is hot enough [6,7]. For a more detailed discussion on plasma ablation, refer to [8] and the references therein.

Substantial shot-to-shot variation is a problem for quantitative LIBS analysis. Plasmas created on identical samples can have different temperatures which affect emission line intensities [9]. Subtle changes in experimental conditions and surface composition can cause these temperature variations. To improve results, averages are generated by repeatedly measuring the same sample. The average spectra can then provide quantitative information on the composition of the sample.

The use of multiple LIBS pulses has been employed for different purposes. One use is removing surface layers off various materials. The LIBS laser is focused on the same surface position, and multiple pulses are used with spectroscopy feedback to determine when the surface layer has been successfully removed. Costela et al. [10] cleaned graffiti off urban buildings with minimal damage to the surface of the building. Li et al. [11] removed cobalt from tungsten carbide hardmetal. Diego-Vallejo et al. [12] used linear correlation and artificial neural networks to determine when the top layers of solar cells had been removed. Majewski et al. [13] cleaned contaminants from thermal barrier coatings, and Roberts et al. [14] removed rock-covering fossils. Maravelaki et al. [15] cleaned Pentelic marble covered in encrustations. Acquaviva et al. [16] cleaned the bust of St. Gregory the
Armenian of contaminants. Flores et al. [17] removed spines from prickled pears without visible damage to the pear, and Bengtsson et al. [18] cleaned salt off high-voltage insulators.

Another use of multiple LIBS pulses is depth profiling. Martelli et al. [19, 20] determined the different tissues in wheat by looking at the Mg II $279.55 \mathrm{~nm}$ to $\mathrm{Mg}$ I $285.22 \mathrm{~nm}$ intensity ratio as repetitive shots were taken at the same location. Abdelhamid et al. [21] investigated the effects of laser irradiance and working distance of a sample looking at how the intensity of $\mathrm{Cu}$ I $465.1 \mathrm{~nm}$ and $\mathrm{Au} \mathrm{I} 431.5 \mathrm{~nm}$ changed after repetitive shots. Theodorakopoulos and Zafiropulos [22] looked at depth profiles of varnishes using the $\mathrm{C}_{2}$ swan band. De Bonis et al. [23] observed the change in the ratio formed by Cu I $282.35 \mathrm{~nm}$ and Sn I $283.94 \mathrm{~nm}$ for an increasing number of shots on a corroded copper tin alloy. Most of the studies mentioned above used more than 100 pulses because of the small amount of surface material removed. The effects of heat propagation on the underlying surface were not addressed because they were irrelevant for the purposes employed. The heat distribution is determined by laser pulse parameters [8] and the optical coupling efficiency of the material. The ablation site can have differences compared to the original surface. These differences include melted and recondensed matter which no longer exhibits the original sample composition. Surface reflectivity and surface breakdown threshold change [7]. This is caused by high-power density pulses, heat, stress, and pressure during the plasma formation [24]. Inside the ablation crater, there is also recondensed material from the plasma [4]. The study presented in this paper utilizes the heat, stress, and pressure created by multiple plasma formations to change the surface properties to a desired state.

LIBS has previously been used as a process-monitoring technique. Boué-Bigne [25] investigated segregation and decarburization using LIBS on polished high-carbon steel. Elemental maps of the surfaces were produced using individual emission lines. One map created using a neutral manganese line was normalized with a neutral iron line removing the baseline gradient. Cabalín and Laserna [26] used pulsed laser deposition to coat silicon with manganin. They produced multielemental maps to monitor the coating constituents. Pedarnig et al. [27] utilized LIBS for in situ monitoring of plasma emission on thin-film deposition. Emission lines of interest were normalized by neutral and ionized yttrium lines and a neutral zinc line. Gruber et al. [28] designed a LIBS system for in situ analysis of solid and molten metals. Chromium, copper, manganese, and nickel were investigated using iron lines as an internal standard. Gruber et al. [29] also performed LIBS analysis on molten metal for chromium, nickel, and manganese but under a vacuum. Lopez-Moreno et al. [30] created a stand-off LIBS system to analyze molten metal as an in-process control. Quantitative analysis of chromium, nickel, and manganese was performed on steel samples at $1000^{\circ} \mathrm{C}$. The present work investigates LIBS as a method for real-time monitoring of the amount of sintering taking place as a result of the LIBS process.

1.2. Internal Standards. In theory, taking a ratio of two emission lines can compensate for the fluctuations in the 
amplitude of spectra caused by experimental conditions. This is referred to as an internal reference, where all emission lines of interest are normalized using a single emission line. The emission line used as a reference is usually from an element with a constant concentration or of an element that makes up the majority of the plasma [6]. The sample can also be spiked with a foreign element of constant concentration, which can be used as a reference. An important consideration is to choose lines that have similar upper level electron energies $\left(E_{k}\right)$. This will reduce the temperature effects, which cause large deviations in emission intensities. Temperature characteristics of each line need to be considered if variations are to be minimized. The magnitudes of the emission lines are to be comparable to reduce the statistical uncertainties produced by combining the percentage uncertainties of each signal. An example of this problem would be combining a strong line with a weak line. The percentage uncertainty, which is used to compute the resulting variance, would be larger for the weak line producing a high uncertainty.

This study investigates the use of multiple LIBS pulses, for postprocessing, to improve the outer surface of Ti MIM samples with complex geometry. This is achieved by the removal of residual carbon (compounds) from and below the surface thus enabling full coalescence. This process will be controlled by spectral feedback from the carbon and titanium lines. The hypothesis is that the heat caused by the LIBS process, from multiple pulses, is sufficiently high that the amount of surface sintered is relatively large compared to the ablated material. This would allow laser sintering and measurement of surface properties at the same time.

\section{Experimental Setup}

A commercial Spectrolaser 4000 unit (Laser Analysis Technologies, Australia) containing a Nd:YAG laser operating at $1064 \mathrm{~nm}$ with a pulse width of $7 \mathrm{~ns}$ and pulse energies of 50 , 100 , and $200 \mathrm{~mJ}$ was focused at a fixed distance perpendicular to the sample surface to generate the plasma. The spot diameter was about $650 \mu \mathrm{m}$, which results in an irradiance of about $8.6 \mathrm{GW} \mathrm{cm} \mathrm{cm}^{-2}$ at $200 \mathrm{~mJ}$ per pulse. The wavelength range of $185.25-948.80 \mathrm{~nm}$ was captured by the four spectrometers inside the Spectrolaser unit. The spectrometers were set to integrate for $1 \mathrm{~ms}$ after a $1.27 \mu$ s delay from the onset of the laser pulse. This system can reach high laser pulse energies but does not allow changing of the lens-tosample distance. The setup was used to investigate the effect that laser pulse energy has on thermally debound injectionmolded titanium samples.

A second commercial system (LIBS-6, Applied Photonics, UK) containing a Nd:YAG laser (Big Sky Ultra, Quantel, France) with the same wavelength, pulse width, delay, and integration time as the Spectrolaser was set to $100 \mathrm{~mJ}$ per pulse. The built-in beam expander was focused to produce a spot size on the sample of $450 \mu \mathrm{m}$, roughly $80 \mathrm{~mm}$ from the beam expander producing an irradiance of $9.0 \mathrm{GW} \mathrm{cm}^{-2}$. Each spectrum was acquired with six spectrometers (Avantes, The Netherlands) covering the range $182.26-908.07 \mathrm{~nm}$. A 3-axis translation stage moved the sample into the focal position of the LIBS beam. This system produces less laser pulse energy than the previous one but can change the lens-to-sample distance. The setup was used to demonstrate the selective sintering process at different heights using a simple autofocus system.

The Spectrolaser system was used with a fixed distance to the sample to acquire an average of 100 spectra from different locations on a single thermally debound sample and a singlesintered sample (see Section 2.2 for sample descriptions). Different locations were used to avoid the effects of previous pulses on the same site. Spectra were then acquired by sampling 10 different locations, on the thermally debound sample, 20 times at 50,100, and $200 \mathrm{~mJ}$ per pulse. The second LIBS system was used with the autofocus function enabled to evaluate its use in removing surface carbon on a sample with varying surface height.

A commercial field emission scanning electron microscope (SEM) (Hitachi S-4700, Hitachi High Technologies, USA) with an accelerating voltage of $20 \mathrm{kV}$, emission current of $11,000 \mathrm{nA}$, and a working distance of $11,200 \mu \mathrm{m}$ was used to investigate the morphology of the ablation craters. An energy-dispersive X-ray spectroscopy (EDS) attachment to the SEM (Noran System 6, Thermo Fisher Scientific, USA) was used to compare the composition of the craters to that obtained from the LIBS spectra.

2.1. Autofocus. A $635 \mathrm{~nm}, 4.5 \mathrm{~mW}$, continuous wave laser directed on the ablation site was used in conjunction with a miniature CCD video camera, connected to the LIBS-6 module, to create an autofocus system based on the triangulation method. The laser was aligned so that the axis of the laser beam would intersect with the ablation site. The AForge.NET framework (a library of common computer vision algorithms [31]) was used to filter the image from the camera to only show the beam spot. The centroids of the resulting images (Figures 1(b), 1(d), and 1(f)) were calculated, and a model created to relate the centroid position of the laser spot with the distance from the ablation site. Figure 1(b) corresponds to the sample being too close to the LIBS-6 machine, Figure 1(d) too far from the LIBS6 system, and Figure 1(f) at a distance where the focus of the LIBS beam is directly on the surface of the sample. This set-up was used in a feedback control system to move the vertical translation stage and hold the sample at the correct height.

2.2. Samples. The samples were made using a binder system comprised of polyethylene glycol 8000, polyethylene glycol 20,000 , natural bees wax, linear low-density polyethylene, and polypropylene [32]. The metal powder was commercially pure titanium produced by the hydride-dehydride route with a particle size less than $325 \mu \mathrm{m}$ (Specialty Metallurgical Products Co. Inc., USA). The binder system was combined with the titanium powder to produce a feedstock with a volume fraction of $30 \%$ binder to $70 \%$ metal powder. The feedstock was mixed using a corotating twin screw extruder (ThermoLab, Lab digital, USA) operating $D=16 \mathrm{~mm}$ screws, $L / D=24$, $\omega=0-250 \mathrm{r} / \mathrm{min}$, and $T=30-300^{\circ} \mathrm{C}$. Injection molding was done using a fully hydraulic injection-molding machine 


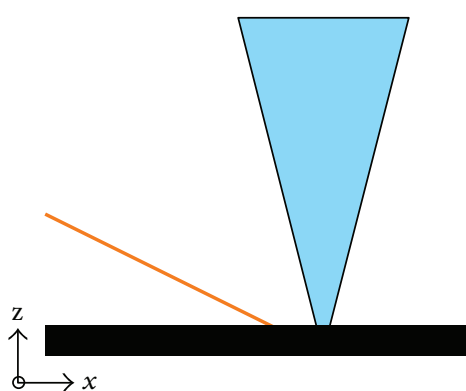

(a)

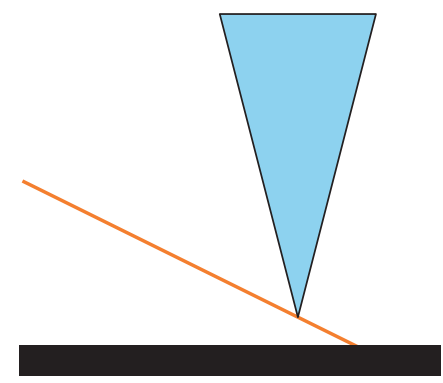

(c)

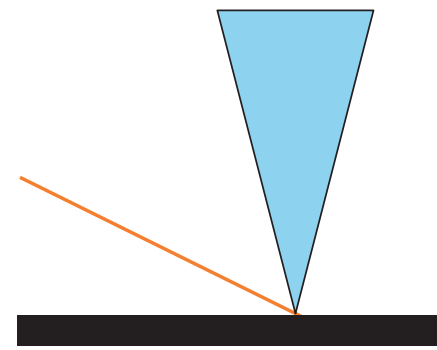

(e)

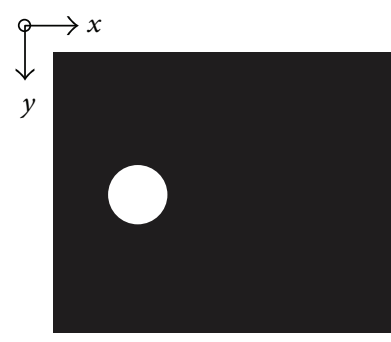

(b)

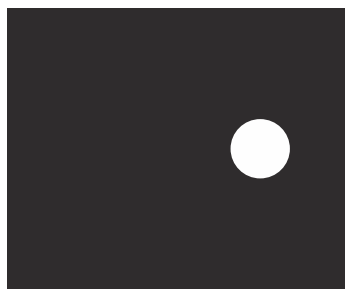

(d)

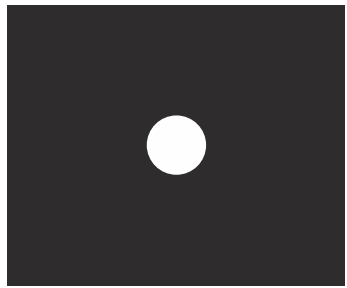

(f)

FIgURE 1: Triangulation method using a $635 \mathrm{~nm}$ CW laser (beam entering from the left). The vertical beam converging on the sample represents the LIBS beam. (a), (c), and (e) show where the autofocus laser strikes the sample surface. (b), (d), and (f) show the camera images of the filtered autofocus laser spots.

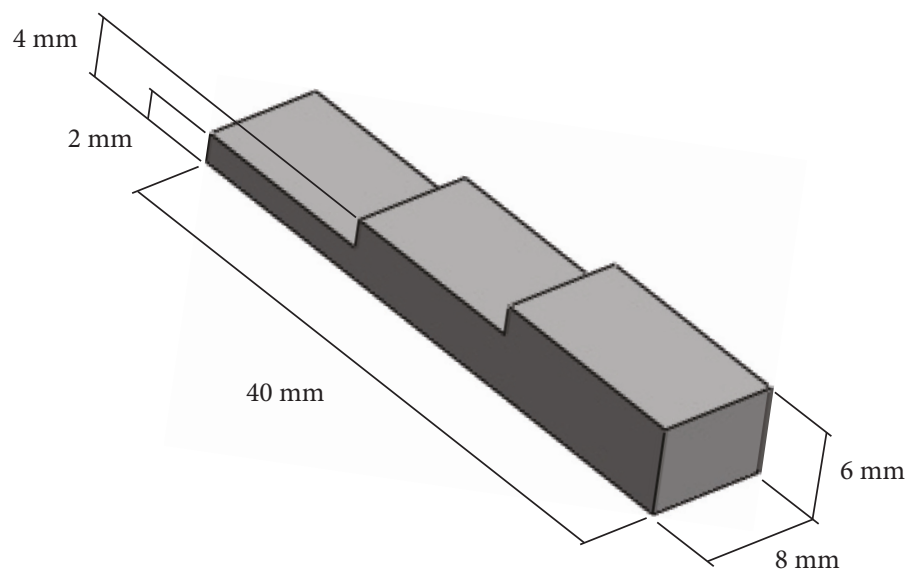

FIGURE 2: Geometry and dimensions for the titanium injection-molded part.

(35 M, Dr Boy, Germany) to create a part shape with complex geometry, that is, with multiple step heights. The dimensions of the part are shown in Figure 2.
Debinding was done using both solvent and thermal processes. A solvent debinding kit (SDK) assembled at the University of Texas-Pan American was used for the test 


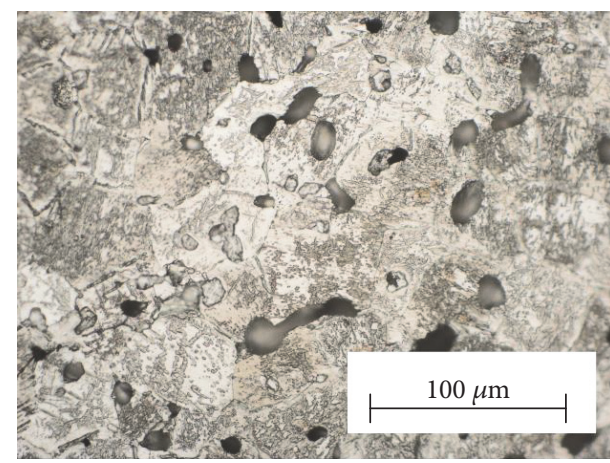

(a)

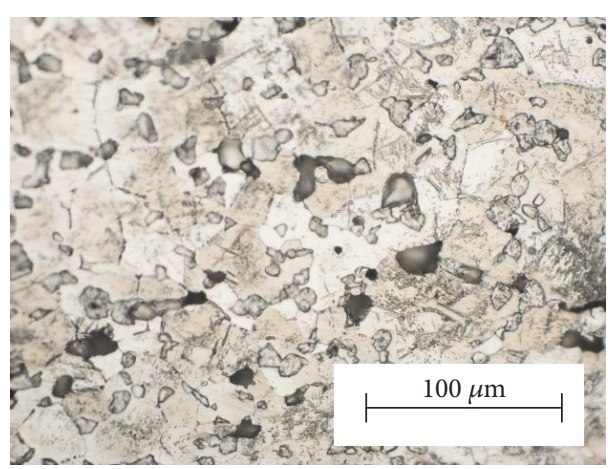

(b)

Figure 3: Microstructure of thermally sintered Ti part prior to laser sintering (a) polished external surface and (b) sectioned and polished internal microstructure.

samples [32]. Thermal debinding was done in a convective drying oven (FED53, Binder, USA) $\left(V=53 \mathrm{~L}, T=30-300^{\circ} \mathrm{C}\right)$ with a gas tight chamber and programmable PID temperature control. After parts were solvent debound, the samples were identified using the designation "TD" for thermal debound (brown parts).

The brown parts were sintered in a furnace (ACME, China) by initial heating with an isothermal period at $470^{\circ} \mathrm{C}\left(\beta=5^{\circ} \mathrm{C} / \mathrm{min}, t=60 \mathrm{~min}\right)$ followed by further heating to $800^{\circ} \mathrm{C}$, all under argon sweep gas $(\dot{V}=10.0 \mathrm{~L} / \mathrm{min})$. This was followed by a further heat increase and a final isothermal period at sinter temperature under vacuum $\left(5^{\circ} \mathrm{C} / \mathrm{min}\right.$, $\left.t=180 \mathrm{~min}, T=1350^{\circ} \mathrm{C}, p=2.0 \times 10-3 \mathrm{mbar}\right)$. The sintered parts were given the designation "S." Both TD and S samples were sanded to remove surface coating and finger print residue. Sectioned and polished $S$ samples were analyzed by X-ray diffraction (XRD) (Empyrean, PANalytical, The Netherlands), with power settings $45 \mathrm{kV}$ at $40 \mathrm{~mA}$ through a copper electrode, scanning from position 20 to $100^{\circ} 2 \theta$, using a step size of $0.026^{\circ} 2 \theta$, scan step time of $17.340 \mathrm{~s}$ in continuous scanning mode. Peak identification was done using the HighScore software (PANalytical, The Netherlands).

\section{Results and Discussions}

3.1. The TD and S Samples. The conventional means of determining binder level during MIM processing is by weighing each sample and comparing the mass to the theoretical value. This method is accurate for most solvent, and thermal debinding processes carried out under $250^{\circ} \mathrm{C}$. However, conventional thermal debinding temperatures are above $420^{\circ} \mathrm{C}$, at which point the thermoplastic binders are reduced to the constituent elements (carbon, oxygen, nitrogen, and hydrogen). Also, at these temperatures, titanium preferentially absorbs those elements with no indication from the component mass. Without destructive testing, it is difficult to determine whether binder residue levels are sufficiently low, and the desired mechanical properties are achieved. Higher elemental levels near the external surfaces can be seen (Figure 3(a)) compared to those internally (Figure 3(b)). The difference arises because the rate of elemental diffusion is slower than the rate of surface deposition once the pores between the particles close during sintering and densities greater than about $94 \%$ are reached.

Even where levels of carbon and oxygen meet specified standards, they may still hinder coalescence of the particles during sintering and cause surface porosity. Surface porosity as seen in Figure 3 reduces the mechanical properties of the final part. The XRD analysis confirmed the presence of carbon and oxygen, as carbide formations, near the external surface [33]. The ability to reduce the elemental levels at the surface should therefore enable a decrease in porosity and subsequent increase in overall density leading to improvements in mechanical properties. Using LIBS to selectively sinter parts of the surface, postprocessing may have the ability to do this.

3.2. Difference in Carbon Content between the TD and $S$ Samples. The average spectra of 100 shots on each of the $\mathrm{TD}$ and $\mathrm{S}$ samples are shown in Figure 4. These spectra were analyzed to find spectral lines that fulfilled the criteria discussed in Section 1.2. Each shot was aimed at different locations on the sample. The emission lines observed in the spectra of the S sample were weaker, and the background continuum was reduced. The $\mathrm{Ti}$ II lines were dominant, and the strong lines of Ti I, which are prevalent between 400 and $600 \mathrm{~nm}$, were significantly reduced. These differences are shown in Figure 4. The UV range, where a number of well-identified Ti lines are present, is highlighted in Figure 5.

Lines that were identified as suitable for internal standardization were C I $247.86 \mathrm{~nm}\left(\mathrm{E}_{\mathrm{k}}=7.685 \mathrm{eV}\right)$ and Ti II $282.81 \mathrm{~nm}\left(\mathrm{E}_{\mathrm{k}}=8.132 \mathrm{eV}\right)$. Taking the ratio of these lines, over all 100 shots on the S sample are 2.45. The C I and Ti II line intensity depends on transition probabilities, electron temperature, and electron density of the plasma, which are governed by highly complex processes in a multicomponent plasma. Time profiles of the species differ as well. As the lifetime of the plasma is shorter than the minimum integration time of the spectrometers, the temporal behavior cannot be analyzed. However, the intensity ratio of the C I/Ti II lines can be calibrated against other measurements, like EDS, and should be useful to determine when enough carbon has been removed. A threshold value of 2.45 was used to indicate when the TD sample had been sintered. At this threshold, the 


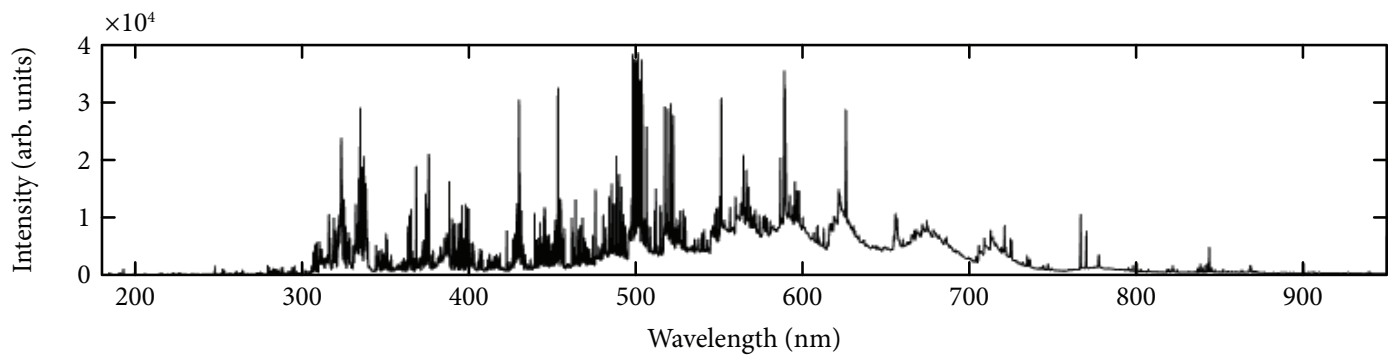

(a)

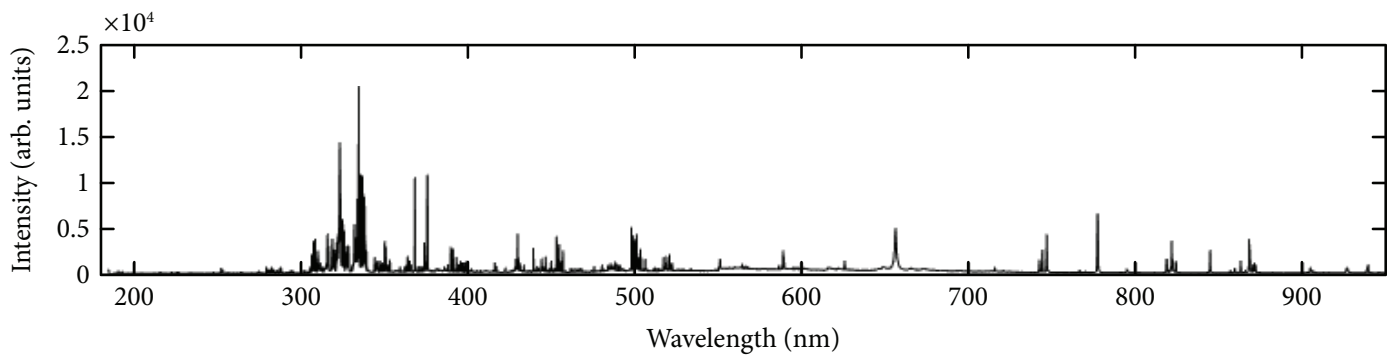

(b)

Figure 4: Average spectra acquired from 100 shots on the TD (a) and S (b) samples. Each shot was on a fresh surface which had not previously been sampled.

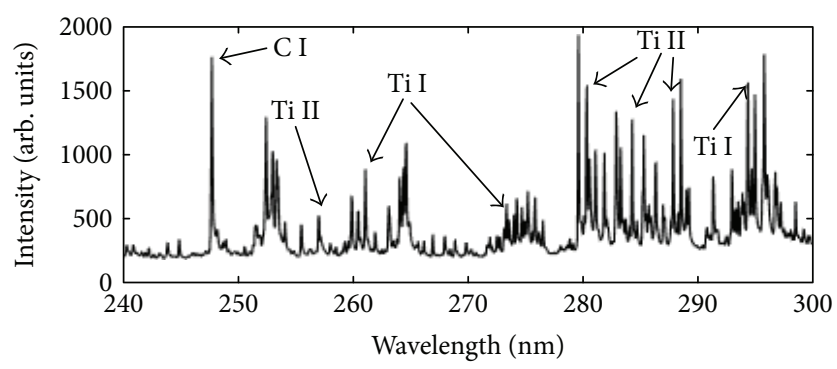

(a)

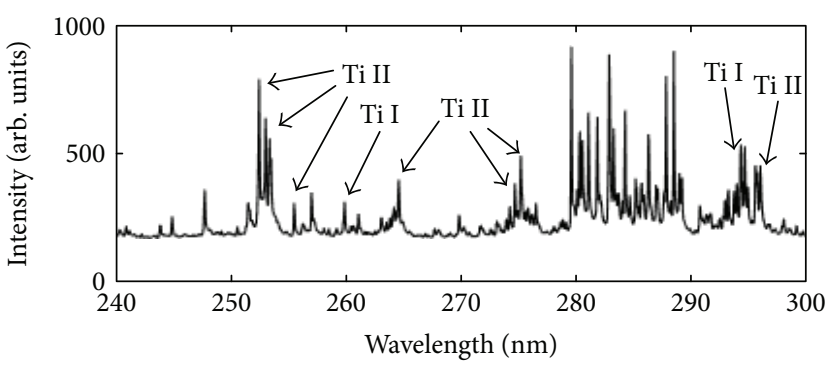

(b)

FIGURE 5: Enlarged section of Figure 4 showing some of the differences between the Ti I and Ti II emissions from the TD (a) and S (b) samples.

TABle 1: Comparison of the Ti and C content.

\begin{tabular}{lcccccc}
\hline & LIBS & & & EDS & \\
& Peak intensity ratio (Ti/C) & C (Wt.\%) & Ti (Wt.\%) & V (Wt.\%) & O (Wt.\%) & Si (Wt.\%) \\
\hline Thermally debound & 0.762 & $20.29 \pm 0.32$ & $74.00 \pm 0.68$ & - & $5.71 \pm 0.56$ & - \\
Sintered & 2.45 & $1.79 \pm 0.24$ & $96.78 \pm 0.69$ & $0.24 \pm 0.24$ & - & $1.19 \pm 0.08$ \\
\hline
\end{tabular}

amount of titanium and carbon in the TD sample surface would resemble that of the $S$ sample.

EDS results show that there is a difference in carbon between the TD sample and the S sample of $18.5 \mathrm{Wt} . \%$. Table 1 displays the results obtained from EDS. When the vanadium content is low, an incorrect concentration for vanadium is determined because of the overlap between the $\operatorname{TiK} \beta(4.93 \mathrm{keV})$ and the $\mathrm{VK} \alpha(4.95 \mathrm{keV})$ peaks in the EDS spectra [34]. The actual vanadium content was determined to be less than $0.01 \% \mathrm{~V}$ from the supplier (Specialty Metallurgical Products Co. Inc., USA). The silicon content is a residue from sanding the sample. The peak intensity ratio of the spectral lines is proportional to the amount of Ti II compared with C I present in the plasma. The amount of titanium in the plasma would be split between Ti I and Ti II. Therefore, the actual concentration ratio, which can be calculated from the EDS results, cannot easily be determined from the spectra without full knowledge of all plasma parameters, like electron temperature and electron density.

3.3. Energy Effects on Multiple Shots. Irradiating an ablation site multiple times with LIBS pulses and comparing the resulting spectra gives information on the amount of sintering taken place. The TD sample was irradiated in 10 different 


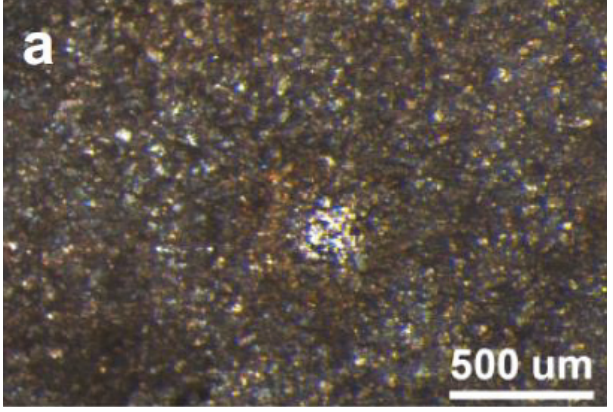

(a)

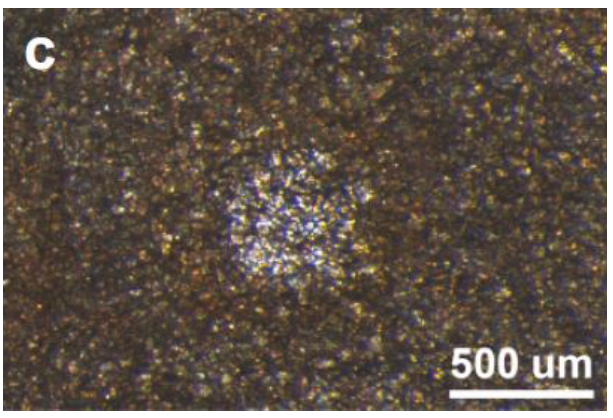

(c)

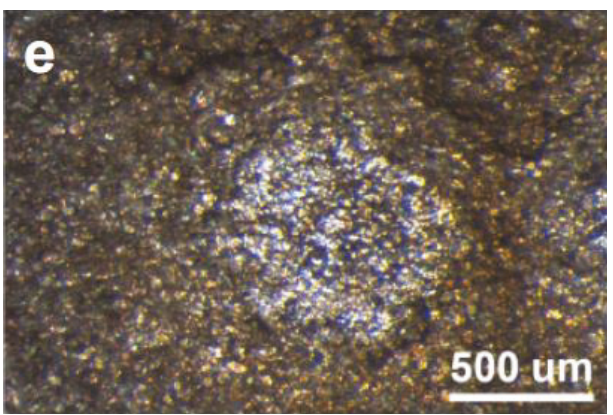

(e)

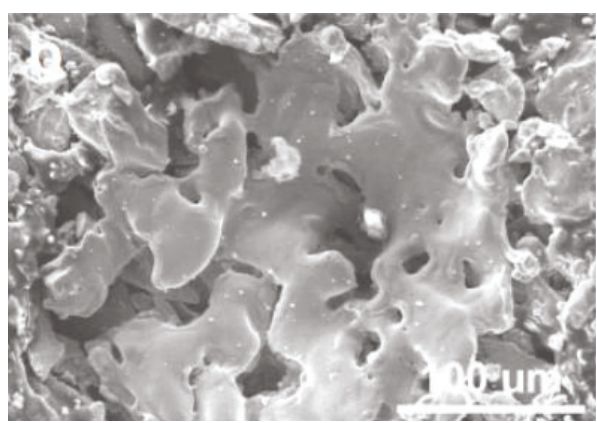

(b)

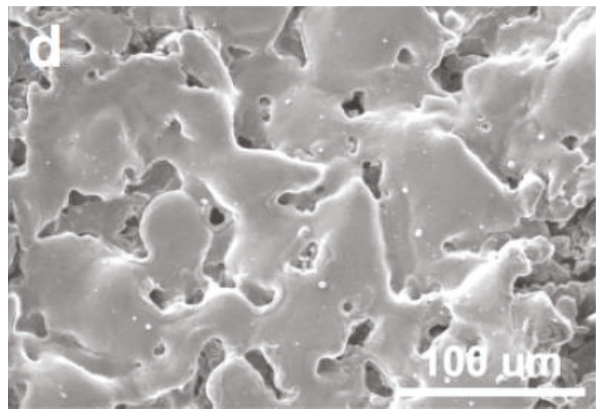

(d)

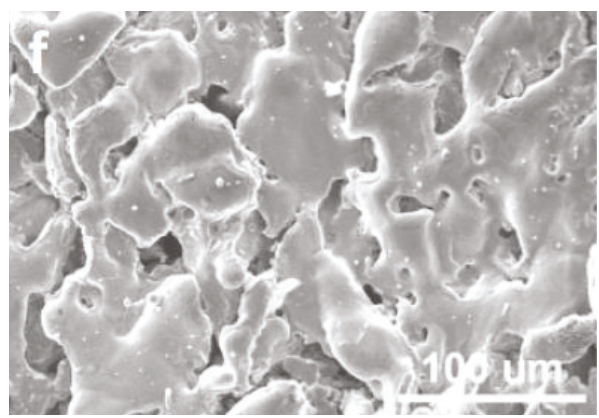

(f)

Figure 6: Ablation craters from 20 consecutive laser pulses using $50 \mathrm{~mJ}$ (a), (b); $100 \mathrm{~mJ}$ (c), (d); and $200 \mathrm{~mJ}(\mathrm{e}),(\mathrm{f})$. (a), (c), and (e) are taken with a SEM (Copyright 2016 Trans Tech Publications Ltd. reprinted with permission [33]).

locations by 20 successive pulses. This process was repeated at different laser pulse energies. The resulting spectra were investigated to determine the effect of laser pulse energy. Figure 6 shows the ablation sites at different laser energies. Figures 6(a), 6(c), and 6(e) are optical microscopy images and Figures 6(b), 6(d), and 6(f) are SEM images. The area being sintered increases as the laser pulse energy increases, as can be seen by the increasing spot in Figures 6(a), 6(c), and 6(e). SEM images of the centers of the ablation craters shown in Figures 6(a), 6(c), and 6(e) are displayed in Figures 6(b), 6(d), and 6(f). These images confirm that sintering has taken place. The edge of the sintered titanium particles are seen in Figure 6(b). The contrast between titanium particles that have and have not been sintered is displayed in Figure 7.

In addition to the line ratio mentioned above, other spectral lines were considered for their suitability to monitor sintering. Sixteen Ti I lines were investigated by calculating the ratio of the $\mathrm{Ti}$ I line intensity to the C I $247.86 \mathrm{~nm}$ intensity. These ratios were normalized then scaled so that they could be compared to the above reference threshold value. Successive sampling using different energies is displayed in Figure 8 for the Ti I $398.18 \mathrm{~nm} / \mathrm{C}$ I $247.86 \mathrm{~nm}$ intensity ratio. The error bars in Figure 8 correspond to the standard deviation of the 10 spectra that were used to find the average ratio for each point on the graph. All other emission line ratios exhibit a trend similar to that of Figure 8 . The small initial value in the first shot may be due to surface contamination. The large fluctuations and error bars are produced by the large difference in $\Delta \mathrm{E}_{\mathrm{k}}$ (difference in $\mathrm{E}_{\mathrm{k}}$ ) between the Ti I lines and C I $247.86 \mathrm{~nm}$ which range from $3.26 \mathrm{eV}$ to $5.29 \mathrm{eV}$. At these high-energy differences, the ratios cannot mitigate the differences in plasma temperature caused by shot-to-shot variations.

Using the same normalizing and scaling procedure as above, $47 \mathrm{Ti}$ II to C I $247.86 \mathrm{~nm}$ intensity ratios were analyzed as well. The wavelengths of the $\mathrm{Ti}$ II lines were between 252.56 and $457.20 \mathrm{~nm}$ and had $\Delta \mathrm{E}_{\mathrm{k}}$ between $-0.39 \mathrm{eV}$ and 


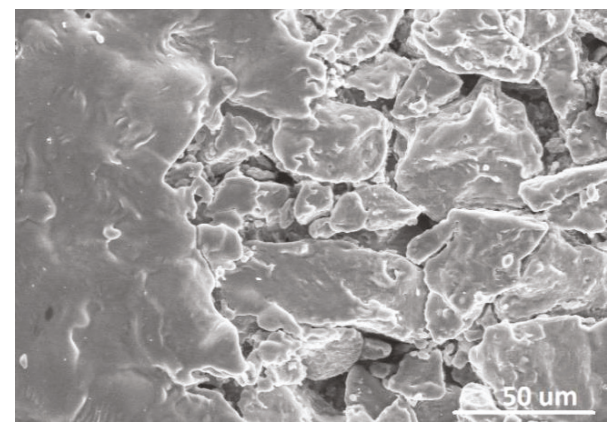

FIGURE 7: SEM showing the edge of sintered titanium. Unsintered particles to the right were not irradiated with the laser beam.

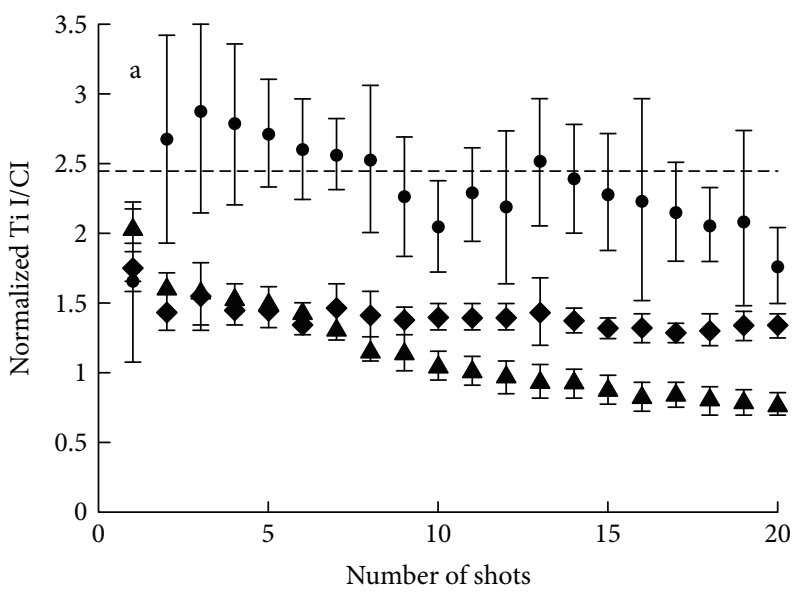

Figure 8: Evolution of the normalized Ti I 398.18 nm/C I 247.86 nm intensity ratio of the thermally debound sample. The dashed line shows the sintering threshold. The different energies used were $200 \mathrm{~mJ}(\bullet), 100 \mathrm{~mJ}(\boldsymbol{\diamond})$, and $50 \mathrm{~mJ}(\boldsymbol{\Delta})$ per pulse.

$4.02 \mathrm{eV}$. A selection of these lines is shown in Table 2, and their variation with the number of $200 \mathrm{~mJ}$ laser shots in Figure 9. After 10 shots, all line ratios are above the sintering threshold.

Using Ti II rather than Ti I, substantial lines improved the sintering prediction. The Ti II lines that produced the best results were $264.59,280.48,281.02,281.78$, and $282.81 \mathrm{~nm}$. Their upper energy level difference to the C I line, $\Delta \mathrm{E}_{\mathrm{k}}$, is between -0.397 and $-0.881 \mathrm{eV}$. All lines followed the trend shown in Figure 10 for the $282.81 \mathrm{~nm}$ line. However, C I $247.86 \mathrm{~nm}\left(\mathrm{E}_{\mathrm{k}}=7.685 \mathrm{eV}\right)$ and Ti II $282.81 \mathrm{~nm}\left(\mathrm{E}_{\mathrm{k}}=8.132 \mathrm{eV}\right)$ was identified as the most robust combination for internal standardization.

Figure 10 shows that $50 \mathrm{~mJ}$ successive shots bring no increase to the titanium to carbon intensity ratio but instead give a slow, steady decline. At $100 \mathrm{~mJ}$, the ratio of peak intensities increases until the tenth shot where the ratio starts to decrease. It is not clear what causes this behavior. At $200 \mathrm{~mJ}$, the intensity ratio increases until it surpasses the threshold of the $S$ sample obtained from Section 3.2. After 10 shots, the threshold value is surpassed, and the TD surface composition is comparable to the $\mathrm{S}$ surface. The reason the
TABle 2: Ionized titanium emission lines used in Figure 9.

\begin{tabular}{lcc}
\hline$\lambda(\mathrm{nm})$ & $\mathrm{E}_{\mathrm{k}}(\mathrm{eV})$ & $\Delta \mathrm{E}_{\mathrm{k}}$ \\
\hline 253.13 & 5.03 & 2.65 \\
264.59 & 8.57 & -0.88 \\
281.02 & 8.10 & -0.41 \\
283.22 & 4.95 & 2.73 \\
351.08 & 5.42 & 2.26 \\
352.03 & 5.57 & 2.12 \\
353.54 & 5.57 & 2.12 \\
362.48 & 4.64 & 3.04 \\
416.36 & 5.57 & 2.12 \\
433.79 & 3.94 & 3.75 \\
450.13 & 3.87 & 3.82 \\
\hline
\end{tabular}

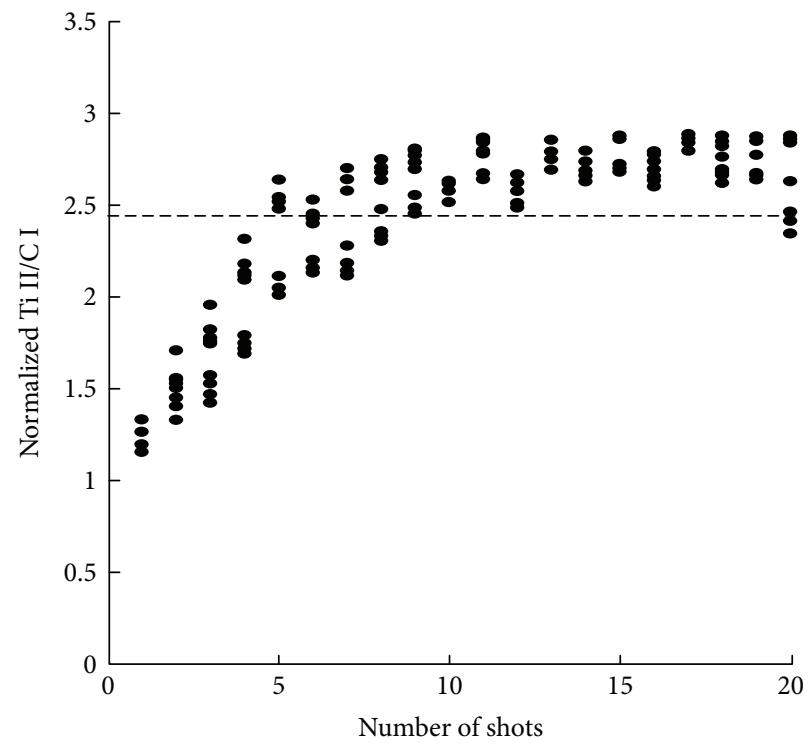

FIgUre 9: Evolution of multiple Ti II lines (Table 2) for a laser pulse energy of $200 \mathrm{~mJ}$. Each point is an average of 10 shots. The dashed line shows the sintering threshold.

ratio continues to increase for $200 \mathrm{~mJ}$ is that the highpower density produced by the $200 \mathrm{~mJ}$ pulse raises the temperature in the sample through heating from the LIBS beam during plasma formation. The heat on the surface starts the sintering process, removing residual binder and fusing together the titanium particles. As the number of laser pulses increases, particle fusion increases. The particle fusion and necking in Figures 6, 7, and 11 are evidence that the surface has been sintered.

EDS results (Table 3 ) of the ablation crater created from the $200 \mathrm{~mJ}$ treatment (Figure 6(e)) show that the carbon content after 20 shots has reduced from $20.29 \mathrm{Wt} \%$ to $2.13 \mathrm{Wt} . \%$ which is comparable to the S sample. The area examined by EDS is presented in Figure 6(f). This confirms the reduction in carbon seen in the titanium to carbon intensity ratio obtained from the LIBS spectra. These results show that there is enough heat penetrating into the sample 


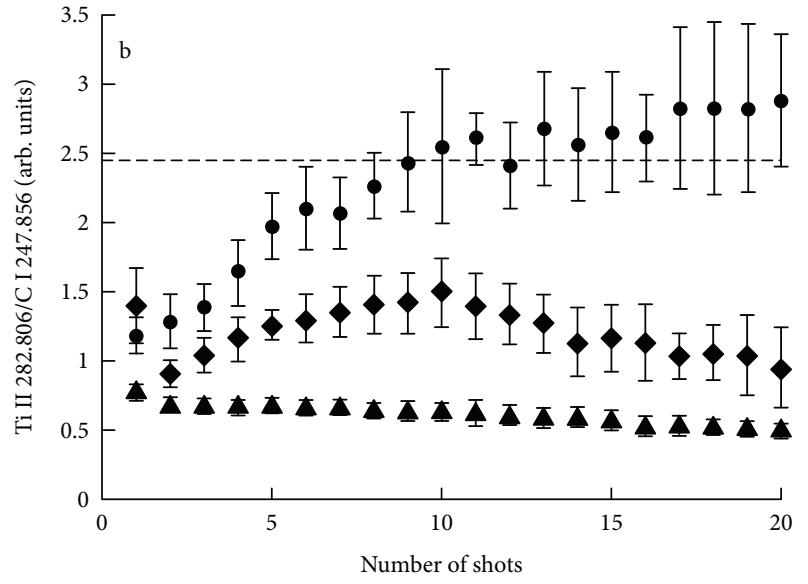

FIGURE 10: Evolution of the peak intensity ratio for Ti II $282.81 \mathrm{~nm} /$ C I $247.86 \mathrm{~nm}$ on the thermally debound sample. The dashed line shows the sintering threshold. The different energies used were $200 \mathrm{~mJ}(\bullet), 100 \mathrm{~mJ}(\boldsymbol{\bullet})$, and $50 \mathrm{~mJ}(\boldsymbol{\Delta})$.

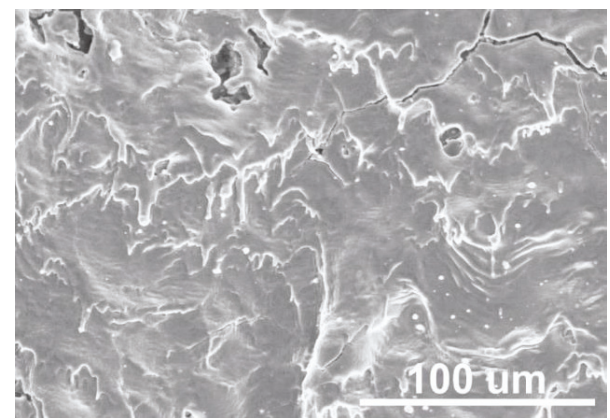

FIGURE 11: SEM image of sintering resulting from slowly moving the LIBS- 6 beam after 10 shots.

creating sintering with very small removal of surface material due to plasma formation.

3.4. Reduction of Carbon Signal in LIBS Spectra. The focal position of the LIBS beam was positioned on the surface of the TD sample. The spot size of the laser, determined from the ablation crater, is approximately $650 \mu \mathrm{m}$ in diameter. When successive shots are fired, sintering expands until it fills the entire spot size of the incident laser. The high-carbon content correlates to the unsintered part of the surface being sampled and is reduced as the area being sampled fuses together. When the entire area under the laser spot is sintered, the $\mathrm{Ti} / \mathrm{C}$ ratio resembles that of sintered titanium.

It can be seen from the SEM images in Figure 6 that there has been sintering in all ablation craters from 50,100 , and $200 \mathrm{~mJ}$ laser pulses even though the LIBS intensity ratio does not reach the threshold value of the $S$ sample. After 20 shots at $50 \mathrm{~mJ}$, there is a sintered spot in the middle of the ablation crater which is about $250 \mu \mathrm{m}$ in diameter. Because of the low laser energy, there is not enough heat generated on the surface of the sample to produce particle fusion over the
TABle 3: Sample composition after repetitive shots compared to traditional sintering. Results obtained from EDS.

\begin{tabular}{lcccc}
\hline & $\mathrm{C}(\mathrm{Wt} . \%)$ & $\mathrm{Ti}(\mathrm{Wt} . \%)$ & $\mathrm{V}(\mathrm{Wt} . \%)$ & $\mathrm{Si}(\mathrm{Wt} . \%)$ \\
\hline Ablation crater & $2.13 \pm 0.26$ & $97.27 \pm 0.84$ & $0.59 \pm 0.32$ & - \\
Sintered & $1.79 \pm 0.24$ & $96.78 \pm 0.69$ & $0.24 \pm 0.24$ & $1.19 \pm 0.08$ \\
\hline
\end{tabular}

entire spot size of the laser. Subsequent shots would still be sampling the carbon in the unsintered part of the ablation crater, and the $\mathrm{Ti} / \mathrm{C}$ ratio does not reach the threshold value. The $100 \mathrm{~mJ}$ crater shows similar results with a slightly bigger sintered spot.

3.5. Implementation. The LIBS-6 system, coupled with the autofocus unit and 3-axis translation stage, was used to produce sintering on the surface of the sample steps at heights of 2, 4, and $6 \mathrm{~mm}$ (see Figure 12). The Spectrolaser system produced sintering at $200 \mathrm{~mJ}$ per pulse, with an irradiance of $8.6 \mathrm{GW} \mathrm{cm}{ }^{-2}$. Using the LIBS 6 system, which has a smaller spot size, increases irradiance on the sample causing higher temperatures and increased localized heating on the surface of the sample. With a pulse energy of $100 \mathrm{~mJ}$, an irradiance of $9.0 \mathrm{GW} \mathrm{cm} \mathrm{cm}^{-2}$ is produced which is comparable to the Spectrolaser system. Therefore, the LIBS-6 system will provide the same heat that the Spectrolaser system produces, entirely sintering the spot area after 10 shots.

The results of sintering a line on the TD sample using the LIBS- 6 system and the ratio threshold of 2.45 to control the process are displayed in Figures 11 and 12. The LIBS-6 system had a spot diameter of $450 \mu \mathrm{m}$ and a repetition rate of $20 \mathrm{~Hz}$ with the sample stage moving at a speed of roughly $0.4 \mathrm{~mm} / \mathrm{s}^{-1}$. It can be seen that the titanium particles have fused together forming a solid mass. After sintering had taken place, on an ablation site, the LIBS beam was moved to a new surface which overlapped the previous spot. Sintering was then repeated on the new surface. The liquid titanium formed on the new spot flowed over the previously sintered spot and has fused together. These regions are seen in Figure 11. This process was repeated until a sintered line was produced across the sample. Figure 12 shows the effectiveness of pulsed laser sintering a line across injectedmolded titanium at step heights of 6,4 , and $2 \mathrm{~mm}$ using autofocus. The effect of heat propagation through the part can be seen by the titanium bluing.

\section{Conclusions}

LIBS has been proven useful for sintering-selected surfaces of injection-molded titanium. The LIBS beam, plasma, and residual heat of the sample surface all contribute to the heating of the injection-molded titanium causing sintering. By observing the C I $247.856 \mathrm{~nm}$ and the Ti II $282.806 \mathrm{~nm}$ lines and then comparing the intensity ratio to that of a conventionally sintered sample, the amount of sintering taking place can be determined. Repetitive shots continue heating the surface and provide spectral feedback to monitor whether the sintering process is complete. The effectiveness 

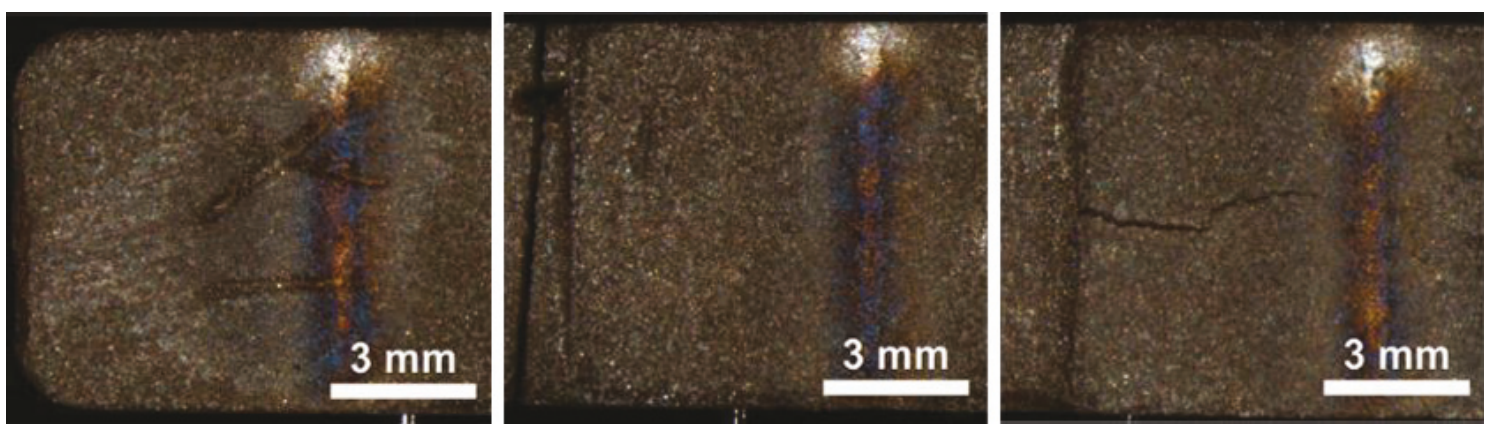

Figure 12: Optical micrograph of line sintering at different step heights. Left to right: 2, 4, and $6 \mathrm{~mm}$ step heights.

of using LIBS to determine when the sample has been sintered has been verified using EDS and SEM images. EDS results show a $18.5 \mathrm{Wt}$ \% reduction in carbon content. It was found that 10 shots at an irradiance between 8.6 and $9.0 \mathrm{GW} \mathrm{cm}{ }^{-2}$ is sufficient to sinter the spot produced by the LIBS beam.

Using the triangulation method described, an autofocus mechanism was produced and calibrated to the LIBS- 6 system. This system was used on an injection-molded grey part with varying step heights to prove the viability of using LIBS in a production process on metal parts with complex geometry. Sintered lines were produced on different step heights of an injection-molded sample. The heat from repetitive plasma formations has colored the previously sintered titanium.

\section{Additional Points}

Highlights. The amount of sintering under a laser spot is evaluated using LIBS. Spectral measurements determine the relative titanium to carbon content. LIBS and Energydispersive X-ray Spectroscopy results display a reduction in carbon contents on the sintered surface.

\section{Conflicts of Interest}

The authors declare that they have no conflicts of interest.

\section{Acknowledgments}

The authors would like to acknowledge and offer continuing respect and admiration to deceased colleague Dr. Sadhana Talele, who was not able to see this work completed. This work was supported by New Zealand's Ministry of Business, Innovation and Employment under contract C11X1209.

\section{References}

[1] J. Beddoes and M. J. Bibby, "6 - powder metallurgy," in Principles of Metal Manufacturing Processes, J. Beddoes and M. J. Bibby, Eds., pp. 173-189, Butterworth-Heinemann, Oxford, 1999.

[2] T. Ebel, "17 - metal injection molding (MIM) of titanium and titanium alloys," in Handbook of Metal Injection Molding, D. F. Heaney, Ed., pp. 415-445, Woodhead Publishing, Cambridge, United Kingdom, 2012.
[3] A. Simchi, "Direct laser sintering of metal powders: mechanism, kinetics and microstructural features," Materials Science and Engineering A, vol. 428, pp. 148-158, 2006.

[4] D. Cremers and L. Radziemski, "Introduction," in Handbook of Laser-Induced Breakdown Spectroscopy, p. 3, John Wiley \& Sons Ltd, West Sussex, UK, 2013.

[5] J. F. Ready, "Effects due to absorption of laser radiation," Journal of Applied Physics, vol. 36, pp. 462-468, 1965.

[6] J. P. Singh and S. N. Thakur, "Fundamentals of laser induced breakdown spectroscopy," in Laser-Induced Breakdown Spectroscopy, J. P. Singh and S. N. Thakur, Eds., p. 3, Elsevier, Oxford, UK, 2007.

[7] D. Cremers and L. Radziemski, "Basics of the LIBS plasma," in Handbook of Laser-Induced Breakdown Spectroscopy, D. Cremers and L. Radziemski, Eds., p. 29, John Wiley \& Sons Ltd, West Sussex, UK, 2013.

[8] A. Bogaerts, Z. Chen, R. Gijbels, and A. Vertes, "Laser ablation for analytical sampling: what can we learn from modeling?" Spectrochimica Acta Part B: Atomic Spectroscopy, vol. 58, pp. 1867-1893, 2003.

[9] U. Panne, C. Haisch, M. Clara, and R. Niessner, "Analysis of glass and glass melts during the vitrification process of fly and bottom ashes by laser-induced plasma spectroscopy. Part I: normalization and plasma diagnostics," Spectrochimica Acta Part B: Atomic Spectroscopy, vol. 53, pp. 1957-1968, 1998.

[10] A. Costela, I. García-Moreno, C. Gómez, O. Caballero, and R. Sastre, "Cleaning graffitis on urban buildings by use of second and third harmonic wavelength of a Nd: YAG laser: a comparative study," Applied Surface Science, vol. 207, pp. 86-99, 2003.

[11] T. Li, Q. Lou, Y. Wei, F. Huang, J. Dong, and J. Liu, "Laserinduced breakdown spectroscopy for on-line control of selective removal of cobalt binder from tungsten carbide hardmetal by pulsed UV laser surface ablation," Applied Surface Science, vol. 181, pp. 225-233, 2001.

[12] D. Diego-Vallejo, D. Ashkenasi, A. Lemke, and H. J. Eichler, "Selective ablation of Copper-Indium-Diselenide solar cells monitored by laser-induced breakdown spectroscopy and classification methods," Spectrochimica Acta Part B: Atomic Spectroscopy, vol. 87, pp. 92-99, 2013.

[13] M. S. Majewski, C. Kelley, W. Hassan, W. Brindley, E. H. Jordan, and M. W. Renfro, "Laser induced breakdown spectroscopy for contamination removal on engine-run thermal barrier coatings," Surface and Coatings Technology, vol. 205, pp. 4614-4619, 2011.

[14] D. E. Roberts, A. du Plessis, J. Steyn, L. R. Botha, S. Pityana, and L. R. Berger, "An investigation of Laser Induced Breakdown Spectroscopy for use as a control in the laser removal 
of rock from fossils found at the Malapa hominin site, South Africa," Spectrochimica Acta Part B: Atomic Spectroscopy, vol. 73, pp. 48-54, 2012.

[15] P. V. Maravelaki, V. Zafiropulos, V. Kilikoglou, M. Kalaitzaki, and C. Fotakis, "Laser-induced breakdown spectroscopy as a diagnostic technique for the laser cleaning of marble," Spectrochimica Acta Part B: Atomic Spectroscopy, vol. 52, pp. 41-53, 1997.

[16] S. Acquaviva, M. L. De Giorgi, C. Marini, and R. Poso, "A support of restoration intervention of the bust of St. Gregory the Armenian: compositional investigations by laser induced breakdown spectroscopy," Applied Surface Science, vol. 248, pp. 218-223, 2005.

[17] T. Flores, L. Ponce, M. Arronte, and E. de Posada, "Freerunning and Q: switched LIBS measurements during the laser ablation of Prickle Pears spines," Optics and Lasers in Engineering, vol. 47, pp. 578-583, 2009.

[18] M. Bengtsson, R. Grönlund, M. Lundqvist, A. Larsson, S. Kroöll, and S. Svanberg, "Remote laser-induced breakdown spectroscopy for the detection and removal of salt on metal and polymeric surfaces," Applied Spectroscopy, vol. 60, pp. 1188-1191, 2006.

[19] M. R. Martelli, C. Barron, P. Delaporte, G. Viennois, X. Rouau, and A. Sadoudi, "Pulsed laser ablation: a new approach to reveal wheat outer layer properties," Journal of Cereal Science, vol. 49, pp. 354-362, 2009.

[20] M. R. Martelli, F. Brygo, P. Delaporte, X. Rouau, and C. Barron, "Estimation of wheat grain tissue cohesion via laser induced breakdown spectroscopy," Food Biophysics, vol. 6, pp. 433-439, 2011.

[21] M. Abdelhamid, S. Grassini, E. Angelini, G. M. Ingo, and M. A. Harith, "Depth profiling of coated metallic artifacts adopting laser-induced breakdown spectrometry," Spectrochimica Acta Part B: Atomic Spectroscopy, vol. 65, pp. 695-701, 2010.

[22] C. Theodorakopoulos and V. Zafiropulos, "Depth-profile investigations of triterpenoid varnishes by $\mathrm{KrF}$ excimer laser ablation and laser-induced breakdown spectroscopy," Applied Surface Science, vol. 255, pp. 8520-8526, 2009.

[23] A. De Bonis, B. De Filippo, A. Galasso, A. Santagata, A. Smaldone, and R. Teghil, "Comparison of the performances of nanosecond and femtosecond Laser Induced Breakdown Spectroscopy for depth profiling of an artificially corroded bronze," Applied Surface Science, vol. 302, pp. 275-279, 2014.

[24] F. O. Leme, Q. Godoi, P. H. M. Kiyataka, D. Santos, J. A. M. Agnelli, and F. J. Krug, "Effect of pulse repetition rate and number of pulses in the analysis of polypropylene and high density polyethylene by nanosecond infrared laser induced breakdown spectroscopy," Applied Surface Science, vol. 258, pp. 3598-3603, 2012.

[25] F. Boué-Bigne, "Laser-induced breakdown spectroscopy applications in the steel industry: rapid analysis of segregation and decarburization," Spectrochimica Acta Part B: Atomic Spectroscopy, vol. 63, pp. 1122-1129, 2008.

[26] L. M. Cabalín and J. J. Laserna, "Surface stoichiometry of manganin coatings prepared by pulsed laser deposition as described by laser-induced breakdown spectrometry," Analytical Chemistry, vol. 73, pp. 1120-1125, 2001.

[27] J. D. Pedarnig, J. Heitz, T. Stehrer et al., "Characterization of nano-composite oxide ceramics and monitoring of oxide thin film growth by laser-induced breakdown spectroscopy," Spectrochimica Acta Part B: Atomic Spectroscopy, vol. 63, pp. 1117-1121, 2008.
[28] J. Gruber, J. Heitz, H. Strasser, D. Bäuerle, and N. Ramaseder, "Rapid in-situ analysis of liquid steel by laser-induced breakdown spectroscopy," Spectrochimica Acta - Part B Atomic Spectroscopy, vol. 56, pp. 685-693, 2001.

[29] J. Gruber, J. Heitz, N. Arnold et al., "In situ analysis of metal melts in metallurgic vacuum devices by laser-induced breakdown spectroscopy," Applied Spectroscopy, vol. 58, pp. 457462, 2004.

[30] C. Lopez-Moreno, S. Palanco, and J. J. Laserna, "Calibration transfer method for the quantitative analysis of hightemperature materials with stand-off laser-induced breakdown spectroscopy," Journal of Analytical Atomic Spectrometry, vol. 20, pp. 1275-1279, 2005.

[31] aforgenet.com, "AForge.NET framework," 2012, http://www. aforgenet.com/framework/.

[32] P. Ewart, S. Ahn, and D. Zhang, "Mixing titanium MIM feedstock: homogeneity, debinding and handling strength," Powder Injection Moulding International, vol. 5, pp. 5459, 2011.

[33] P. Ewart, H. Jull, R. Künnemeyer, and P. N. Schaare, "Identification of contamination levels and the microstructure of metal injection moulded titanium," in Key Engineering Materials, T. Ebel and F. Pyczak, Eds., vol. 704, pp. 161-169, Trans Tech Publications Ltd, Zurich, Switzerland, 2016.

[34] J. C. Russ, "Chapter 3 - energy dispersive spectrometers," in Fundamentals of Energy Dispersive X-ray Analysis, J. C. Russ, Ed., pp. 17-41, Butterworth-Heinemann, Oxford, United Kingdom, 1984. 

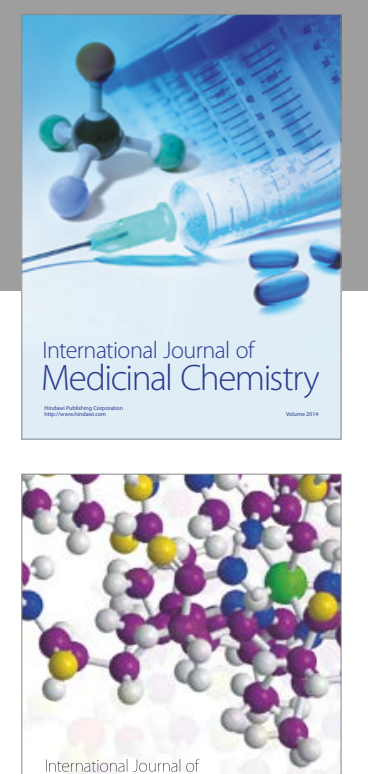

Carbohydrate Chemistry

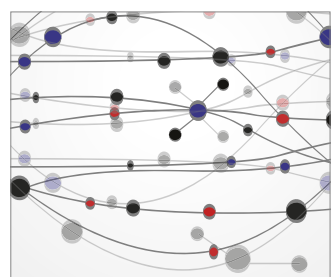

The Scientific World Journal
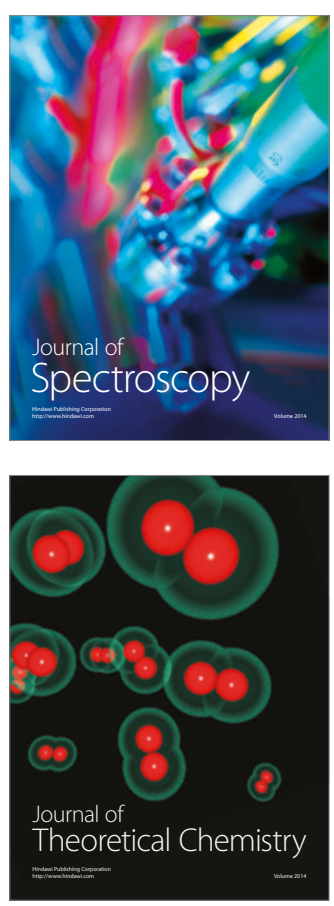
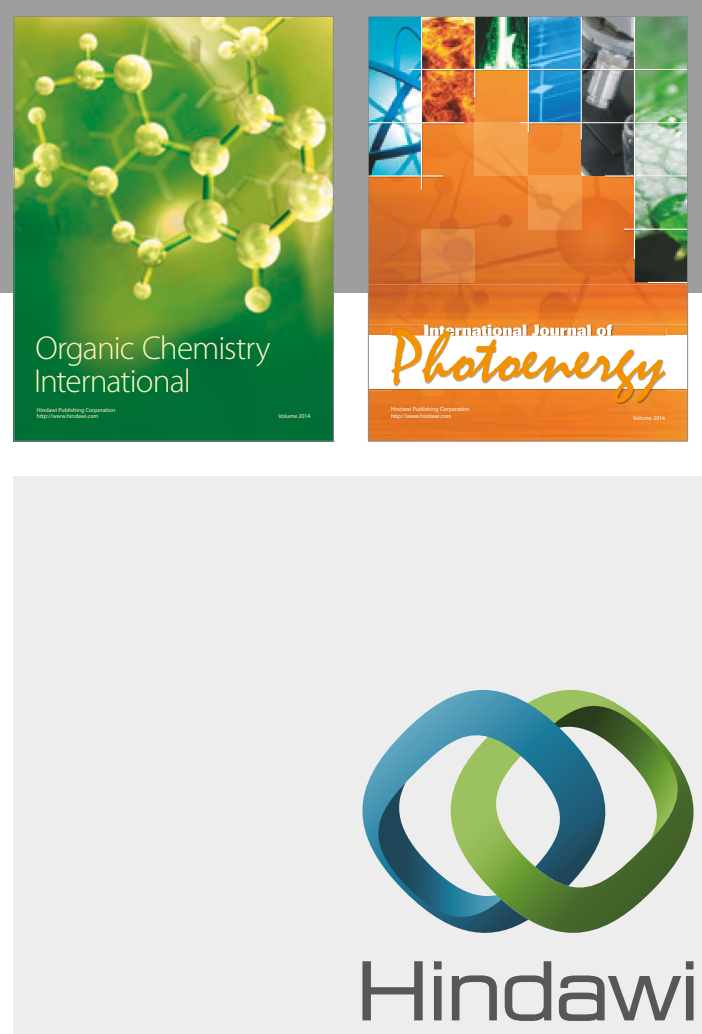

Submit your manuscripts at

https://www.hindawi.com

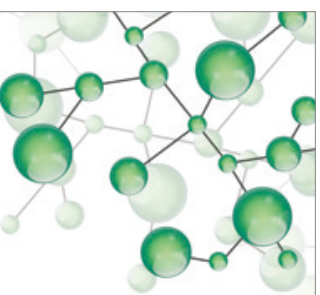

International Journal of

Inorganic Chemistry

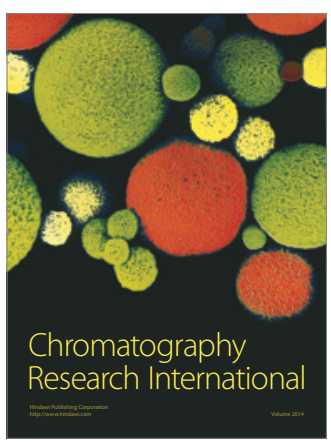

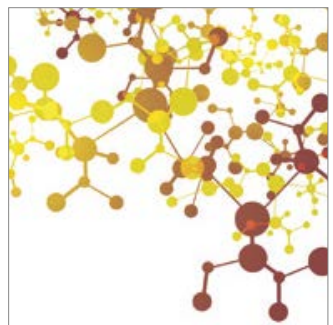

Applied Chemistry
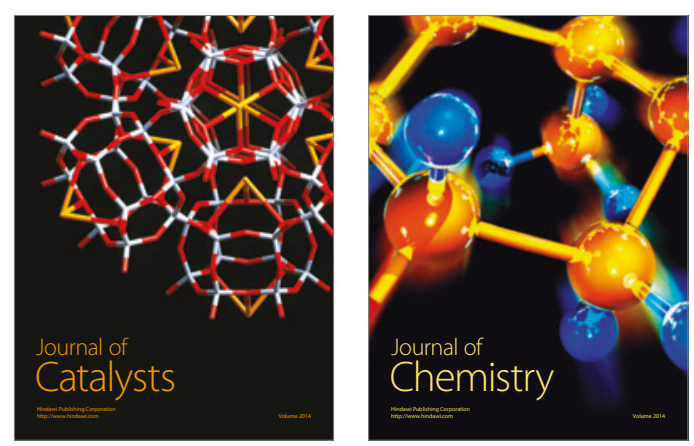
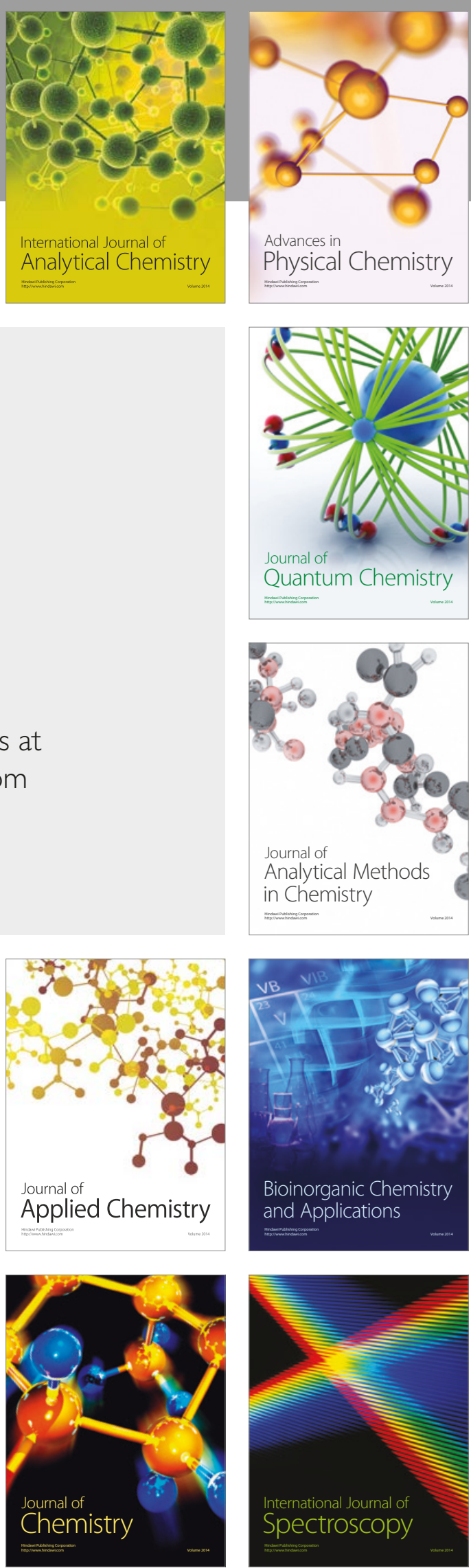